\title{
Ginástica artística e especialização precoce: cedo demais para especializar, tarde demais para ser campeão!
}

CDD. 20.ed. 796.073

796.41

\author{
Myrian NUNOMURA \\ Paulo Daniel Sabino CARRARA** \\ Mariana Harumi Cruz TSUKAMOTO**
}

${ }^{*}$ Escola de Educação Física e Esporte de Ribeirão Preto, Universidade de São Paulo. *Escola de Educação Física e Esporte, Universidade de São Paulo.

\section{Resumo}

Na ginástica artística é comum observarmos ginastas em tenra idade treinando, competindo e obtendo resultados expressivos no âmbito internacional. Assim, frequentemente, a modalidade recebe críticas severas sobre as suas práticas e a necessidade dos ginastas iniciarem o treinamento tão jovens. Mas, no Brasil, ainda há poucos dados sobre a realidade da iniciação e da especialização esportiva na ginástica artística. 0 objetivo do presente estudo foi investigar, entre os técnicos da modalidade, sobre a idade que eles consideram a ideal para o início da prática e a especialização e os respectivos argumentos. Foram entrevistados 46 técnicos do Brasil que trabalham em todas as categorias de formação que visam ao alto nível. Utilizamos a técnica de análise de conteúdo proposta por BARDIN (2001) para o tratamento de dados. Os dados revelam que a prática e a especialização iniciam em tenra idade em ambos os gêneros. Os técnicos do setor masculino e do feminino citam que a especialização precoce ocorre devido à própria natureza da modalidade, à idade de participação em eventos oficiais e ao tempo de preparação necessário para que os ginastas apresentem condições para competir. No setor masculino, em particular, a necessidade dos ginastas de ingressar no mercado de trabalho pressiona os técnicos a obterem resultados antes que eles comecem a abandonar o esporte.

UnItermos: Ginástica artística; Treinamento; Especialização; Especialização precoce.

\section{Introdução}

O crescimento do esporte é um fenômeno mundial (McCullick, Belcher \& SCHEMpr, 2005) que vem repercutindo em todas as esferas da sociedade. Devido à diversidade de opções de práticas esportivas, pais e seus filhos podem ficar indecisos sobre o que praticar, quando iniciar e quando competir. Há afirmaçôes de que quanto mais cedo iniciar no esporte, melhor. Mas, melhor para quem ou em que sentido? Crianças e jovens são atraídos para o esporte e, provavelmente, há aqueles que sonham em chegar ao pódio ou participar dos Jogos Olímpicos, ainda que não conheçam o caminho que deverão percorrer até merecer uma medalha no peito.

O processo de preparação esportiva visa consolidar a funcionalidade do atleta em longo prazo e atingir a excelência na modalidade escolhida em idades superiores. Há sugestões de modelos de formação esportiva na literatura como, por exemplo, BALYI (2003), Bompa (2000), Weineck (1999), Chaurra, Zuluaga e PeÑa (1998) e ZaKharov (1992). A especialização é parte natural desse processo quando os esforços e tempo são canalizados para uma única modalidade, após um período de prática variada. Contrariamente, a especialização precoce refere-se à especialização antes do período considerado ideal, quando fases do processo de formação são antecipadas ou anuladas (Bompa, 2000; MARQUes, 1991; WeINECK, 1999).

A idade de início do treinamento especializado varia de acordo com a cultura e a modalidade esportiva (BOMPA, 2000; ZAKHAROV, 1992), o gênero, a vida útil de prestação esportiva e o ápice esportivo (Carazzato, 1995). Na Ginástica Artística (GA), em particular, muita atenção é necessária, pois, acredita-se que a especialização esportiva seja realmente precoce. O período ótimo de desenvolvimento de capacidades coordenativas e da flexibilidade (ARKAEV \& Suchilin, 2004) e as vantagens biomecânicas de proporções corporais menores (DAMSGAARD, 2001) 
são os argumentos mais utilizados na GA competitiva, mas, ainda assim, levantam críticas e debates, seja na Pedagogia do Esporte ou nas demais áreas.

BOMPA (2000), GONÇALVES (1999) e COELHO (1988) associam a especialização precoce ao fato de muitas pessoas acreditarem que, quanto mais cedo a criança iniciar na modalidade esportiva, mais chances de sucesso ela terá. E, apesar da literatura atual tentar esclarecer essa visão equivocada de especialização e esta associação não encontrar apoio na ciência, a especialização precoce é explorada amplamente no esporte contemporâneo. A especialização precoce é desaconselhada, pois acarreta uma série de consequências negativas aos praticantes como redução do repertório motor; aumento da incidência de lesões (BOMPA, 2000; GaLdino \& MACHADO, 2008; MARQUES, 1991); prejuízos gerais ao desenvolvimento da criança (SEABRA \& CATELA, 1998); manifestação de efeitos psicológicos negativos como o "burnout" (WATTS, 2002); desmotivação (CoElHo, 1988) e prejuízos à formação escolar (WEINECK, 1999).

O treino sistemático inicia-se antes da puberdade nas modalidades artísticas (BALYI, 2003; DAMSGAARD, 2001). Mas, não podemos inferir que seja consenso entre os técnicos de GA que a especialização na modalidade deva ocorrer bem cedo. Entretanto, não raras vezes, técnicos argumentam a "necessidade" e a "obrigatoriedade" de se iniciar os treinamentos sistemáticos e intensivos ainda em tenra idade.

\section{Métodos}

\section{Amostra}

Realizamos uma investigação em campo e entrevistamos 46 técnicos (34 do setor feminino e 12 do masculino) que orientam ginastas das categorias de base da GA, os quais competem em torneios oficiais das respectivas Federações e/ou da Confederação Brasileira de Ginástica (CBG). O recorte foi estabelecido sobre o Estado de São Paulo e cidades do Rio de Janeiro, Curitiba e Porto Alegre, devido à representatividade numérica e qualitativa destas localidades no cenário nacional da GA. O estudo foi aprovado pelo Comitê de Ética em Pesquisa da EEFE/USP.

\section{Procedimentos}

Apoiados em um roteiro pré-estabelecido, os técnicos foram entrevistados, individualmente, e seus
Não há problemas com o treinamento sistematizado quando os ginastas atravessaram todo o processo de preparação e adaptação, até demonstrarem condições de suportar as cargas de treinamento da modalidade. Mas, quando crianças e jovens competem segundo as regras oficiais, surgem questionamentos como: quanto tempo eles treinaram até atingir esse padrão técnico e com que idade iniciaram os treinos? Ainda que as crianças demonstrem talento para a GA, o treinamento intensivo e uni direcionado pode comprometer a saúde e o envolvimento em longo prazo. E, talvez, o seu potencial para o alto rendimento na modalidade jamais seja desenvolvido. $\mathrm{O}$ esporte competitivo tem sua própria característica e a crítica não se reporta à exigência do alto rendimento para adultos, mas, quando estas mesmas exigências são feitas às crianças.

A GA pode contribuir para a formação esportiva geral, pois estimula as capacidades físicas e motoras, que também são importantes para a prática de outras modalidades esportivas. Mas, será que na GA é preciso iniciar cedo os treinamentos especializados para evoluir ao alto nível? Seria uma exigência real da modalidade? Os objetivos do presente estudo foram: 1) analisar a opinião dos técnicos da GA competitiva sobre a idade e o conteúdo ideal para o início da prática e da especialização na modalidade; 2) discutir as respectivas argumentações que sustentam seu ponto de vista sobre a especialização precoce.

depoimentos foram integralmente registrados em miniDV. Solicitou-se que eles relatassem sobre a idade ideal para o início da prática e a especialização na GA e, também, o seu ponto de vista sobre a especialização precoce na GA, justificando as respostas.

Para o tratamento dos dados, optamos pela técnica de análise de conteúdo proposta por BARDIN (2001), que envolve o tratamento bruto dos dados (leitura), a categorização (organização dos dados) e a codificação (definição das unidades de significado e unidades de contexto), para posterior discussão à luz da teoria que circunstancia o fenômeno.

A análise ocorreu, discriminadamente, para o grupo de técnicos do setor feminino e do masculino. Este procedimento foi adotado porque identificamos, entre os sexos, diferenças significativas que demarcam o processo de formação esportiva, como a idade de início e as particularidades do processo de maturação. 


\section{Resultados}

Os dados foram organizados em duas categorias para ambos os sexos: 1) Idade do praticante e 2) Conteúdo das atividades, para cada um dos questionamentos. Os quadros a seguir resumem as opiniōes apresentadas pelos técnicos.

QUADRO 1-Resultados apresentados pelos técnicos do setor feminino.

\begin{tabular}{|c|c|c|}
\hline & Idade & Conteúdo das atividades \\
\hline $\begin{array}{l}\text { Ideal para } \\
\text { iniciar }\end{array}$ & $\begin{array}{l}\text { - Alguns técnicos dizem que, entre 5-7 anos de ida- } \\
\text { de, seria a idade ideal para iniciar. } \\
\text { - Outros mencionam que, entre 3-4 anos de idade, } \\
\text { a criança já deveria frequentar o ambiente da GA. }\end{array}$ & $\begin{array}{l}\text { - Os técnicos lembram a importância das atividades } \\
\text { lúdicas nas etapas inicias. } \\
\text { - No entanto, ao citarem exemplos de atividades, } \\
\text { referem-se a atividades típicas do treinamento espe- } \\
\text { cializado. }\end{array}$ \\
\hline $\begin{array}{c}\text { Ideal para } \\
\text { especializar }\end{array}$ & - De 6-7 a, no máximo, 9-10 anos de idade. & $\begin{array}{l}\text { - Os técnicos alegam que os regulamentos das fede- } \\
\text { raçóes e confederações estimulam a especialização. } \\
\text { - A pressão das instituições para a obtenção de resul- } \\
\text { tados também justifica a necessidade de especializa- } \\
\text { ção, na opinião dos técnicos. } \\
\text { - Alguns técnicos acreditam que a prontidão do atle- } \\
\text { ta pode permitir que a detecção de uma boa resposta } \\
\text { ao treinamento, ainda que este seja iniciado antes da } \\
\text { idade considerada ideal. }\end{array}$ \\
\hline $\begin{array}{l}\text { Ponto de vista } \\
\text { sobre a } \\
\text { especialização } \\
\text { precoce }\end{array}$ & $\begin{array}{l}\text { - Os técnicos concordam que a especialização aos 4-5 } \\
\text { anos de idade seja precoce. } \\
\text { - Ainda assim, muitos se manifestam favoráveis à es- } \\
\text { pecialização entre 4-7 anos de idade. }\end{array}$ & $\begin{array}{l}\text { - A formação do atleta deve ocorrer em longo prazo. } \\
\text { Portanto, alguns técnicos mencionam que não há ra- } \\
\text { zão para apressar este processo. } \\
\text { - Os regulamentos vigentes na modalidade são apon- } \\
\text { tados mais uma vez como uma justificativa para a } \\
\text { propensão à especialização precoce na modalidade. } \\
\text { - Os técnicos apontam o esgotamento e a incidência } \\
\text { de lesões como consequências deste processo. }\end{array}$ \\
\hline
\end{tabular}

QUADRO 2 - Resultados apresentados pelos técnicos do setor masculino.

\begin{tabular}{|c|l|l|}
\hline \multicolumn{2}{|c|}{ Idade } & \multicolumn{1}{c|}{ Conteúdo das atividades } \\
\hline $\begin{array}{c}\text { Ideal para } \\
\text { iniciar }\end{array}$ & $\begin{array}{l}\text { - Entre os 5-7 anos de idade. } \\
\text { - Entre os 3-4 anos de idade, a criança pode começar } \\
\text { a frequentar o ambiente da GA. }\end{array}$ & $\begin{array}{l}\text { - Os técnicos mencionam priorizar atividades que } \\
\text { despertem o gosto pela prática. } \\
\text { - Afirmam que não cobram ou pressionam as crian- } \\
\text { ças para que treinem. }\end{array}$ \\
\hline $\begin{array}{c}\text { Ideal para } \\
\text { especializar }\end{array}$ & - Aproximadamente aos 7 anos de idade. & $\begin{array}{l}\text { - Foco na formação da base motora para a modali- } \\
\text { dade. } \\
\text { - Alguns técnicos mencionam que, em virtude das } \\
\text { características do treinamento, este pode se tornar } \\
\text { monótono e levar ao esgotamento. } \\
\text { - Um pequeno grupo de técnicos demonstra a preo- } \\
\text { cupação em manter a ludicidade e a diversão durante } \\
\text { as aulas. } \\
\text { - O conteúdo das atividades é influenciado pelas exi- } \\
\text { gências dos regulamentos das competiçóes. }\end{array}$ \\
$\begin{array}{c}\text { Ponto de vista } \\
\text { sobre a } \\
\text { especialização } \\
\text { precoce }\end{array}$ & - Os técnicos dizem que a ideia de especialização pre- \\
coce não existe mais no país. & $\begin{array}{l}\text { - Para as crianças mais jovens (entre 4-5 anos de ida- } \\
\text { de), recomenda-se que sejam desenvolvidos elemen- } \\
\text { tos básicos e de coordenação. } \\
\text { - A inserção precoce em situaçóes de treinamento } \\
\text { sistematizado e especializado, consequentemente en- } \\
\text { volverá as crianças em situaçóes competitivas. }\end{array}$ \\
\hline
\end{tabular}




\section{Discussão}

\section{Setor feminino}

\author{
Ideal para iniciar na GA
}

Idade: alguns técnicos citam que é necessário iniciar por volta dos 5-7 anos de idade, o que tem apoio na literatura (ARKAEV \& SUCHILIN, 2004; BOMPA, 2000), enquanto outros alegam que aos 3-4 anos a criança deveria começar a frequentar o ambiente da GA. Uma minoria dos técnicos acredita que não haja argumentação consistente sobre a idade ideal de início na GA e, ainda que estes não concordem, eles parecem seguir o padrão de idade adotado na maioria das instituições. Há técnicos que não citaram idades ou períodos, e estes alegam que a nossa realidade não permite impor limites nem estabelecer padrões cronológicos ideais. Caso contrário, corre-se o risco de perder material humano. Essa visão realista é reforçada por exemplos como a ginasta Daiane dos Santos, que iniciou na GA além da idade ideal recomendada e foi expressão no contexto internacional. Um argumento utilizado pelos técnicos é o fato de considerarem a individualidade dos ginastas e não estabelecer uma idade ideal para iniciar, mas aproveitar o potencial de cada um.

Conteúdo: observamos que alguns técnicos têm considerado o aspecto lúdico nas atividades iniciais, a fim de amenizar o estresse excessivo e o esgotamento das crianças. E, citam que a GA pode se tornar repetitiva e monótona, dependendo das estratégias adotadas. As ações destes técnicos focam no conhecimento e na familiarização com o ambiente da GA. Mas, alguns técnicos se contradizem, pois citam atividades características do treinamento especializado para aqueles que estão iniciando na modalidade. Os técnicos citaram que eles também focam no desenvolvimento motor geral, ainda que seja papel das escolas. Certamente, é um dos pontos críticos para o crescimento do Esporte no nosso país, pois os técnicos precisam preencher esta lacuna da Educação Física Escolar.

Percebemos que os modelos de formação esportiva (Balyi, 2003; Bompa, 2000; Chaurra, Zuluaga \& PeÑa, 1998) se enquadram em um sistema cuja Educação Física Escolar cumpre seu papel, o que raras vezes ocorre no nosso país. A noção de que a formação esportiva é um processo de longo prazo ficou evidente no depoimento de alguns técnicos, e encontra apoio na literatura, pois esta menciona que sejam necessários, em média, de oito a 10 anos de preparação até atingir o pico de rendimento.

\section{Ideal para especializar na GA}

Idade: para os técnicos a especialização deve iniciar entre os 6-7 anos de idade e, no máximo, até os 9-10 anos. As opinióes estão divididas para que a especialização ocorra entre um a cinco anos após o início da prática na GA. As justificativas mais recorrentes são as vantagens das proporções corporais menores de crianças com maturação tardia e os períodos sensíveis em que as capacidades são desenvolvidas, principalmente a coordenativa e a flexibilidade (Léglise, 1996; Nunomura, Pires \& Carrara, 2009; TSUKamoto \& NunOMura, 2003).

Conteúdo: os técnicos alegam que os regulamentos vigentes das federações e confederação induzem à especialização precoce, o que muitas vezes contradiz o seu conceito de formação esportiva. Segundo a literatura (Claessens, Malina, Lefevre, Beunen, Stijnen, Maes \& Veer, 1992; Sobral, 1994) os indícios da especialização precoce são evidentes na GA se comparadas às demais modalidades esportivas. Um dos técnicos citou que tem discutido o fato com a federação e a confederação a fim de reverter este quadro, pois as regras se aplicam às ginastas talentosas e desconsideram aquelas "normais". A exigência das regras também preocupa os demais técnicos, pois está associada à desistência entre as ginastas (Lopes \& NunOMURA, 2007).

A pressão também vem das próprias instituições, pois há expectativa de que o investimento no setor competitivo reverta-se em resultados ainda nas categoriais iniciais. Outra argumentação para a especialização precoce baseia-se nos padrôes internacionais da GA atual de que seja inevitável e essencial especializar cedo para ser competitivo, conforme os depoimentos: "na GA, as crianças não podem acordar muito tarde" (T8), ou que "se não vier com bagagem motora antes dos 12 anos, não vai render o que precisa" (T10), ou "os clubes não pegam crianças com mais de nove anos” (T26), entre outras afirmações que induzem a própria criança e os pais a acreditarem que, mesmo sendo criança, é "velha demais" para a GA competitiva.

A prontidão necessária para o ingresso no sistema de treinamento especializado também foi citada por alguns técnicos. Estes acreditam que se as crianças forem talentosas, estas serão capazes de responder bem às exigências do treinamento especializado, ainda que a literatura considere cedo. $\mathrm{O}$ processo de crescimento e de maturação foi apontado por alguns técnicos como fator negativo, pois dificultaria 
a evolução na GA devido ao aumento das proporções corporais. A desvantagem biomecânica é fato, mas, outras qualidades podem ter efeito compensatório como a melhoria das capacidades físicas, cognitivas e a maturidade psicológica para suportar as demandas.

Contrariamente, alguns técnicos acreditam na vantagem de especializar o atleta mais tarde, a fim de prolongar a participação esportiva da ginasta, e citam que muitas ginastas que iniciaram cedo, também abandonaram cedo. Provavelmente, o abandono tem relação com as altas exigências dos treinamentos e das competições, o que tem apoio da literatura (BRENNER \& COUNSIL on Sports Medicine and Fitness - CSMF, 2007). E, Hedstrom e Gould (2004) e Bompa (2000) citam que não há dados que comprovem que a especialização precoce tenha revelado atletas expoentes nas fases adultas.

Mesmo que seja consenso entre os técnicos de que o caminho para atingir o alto nível na GA seja iniciar cedo, muitos admitem que inúmeros fatores afetam o sucesso no esporte, e citam suas próprias experiências: "Tem lugares que trabalham uma menina talentosa, e começam a forçar para ser campeã brasileira infantil, e quando chega no juvenil a menina tá quebrada, estourada" (T15) como é o caso também de T10 e T28. Assim, ao excluir ginastas do setor competitivo ou simplesmente negar-lhes a oportunidade de demonstrar seu talento pode causar o desperdício de muitos potenciais.

A adaptação ao treinamento tem sido respeitada por alguns técnicos, os quais citam o aumento gradual do tempo de treino à medida que as crianças avançam na idade. Mas, não podemos negar a individualidade das mesmas, especialmente sobre os princípios do treinamento e as respostas individuais (WEINECK, 1999), pois a idade cronológica não é o único parâmetro para prescrever o volume e a intensidade de treino.

Além do início prematuro, entre os 5-6 anos de idade, devemos considerar a quantidade de horas de treino no alto nível, que tem variado entre 24 a 36 horas semanais, distribuídos em cinco ou seis dias por semana (ARKaEv \& SuChILIN, 2004; NunOMUra, Pires \& Carrara, 2009; Richards, Ackland \& ElLiott, 1999). Para crianças pré-púberes ou púberes, o limite sugerido de 15 horas de treino por semana parece razoável (DAMSGAARD, 2001). BRENNER e CSMF (2007) recomendam o limite máximo de cinco dias semanais de atividade esportiva e descanso mínimo de um dia de qualquer atividade física sistematizada. E mais, os atletas deveriam ter, no mínimo, de dois a três meses por ano de férias de sua modalidade. Além das lesões por "overuse", se não houver tempo suficiente para a recuperação suficiente, o jovem poderá estar sob o risco de "burnout".

\section{Ponto de vista sobre a "especialização precoce"}

Segundo os técnicos, a especialização precoce incide sobre a idade, a individualidade, os objetivos de longo prazo, o esgotamento, entre outros aspectos e tem raízes nas tendências internacionais da GA.

Idade: a maioria dos técnicos concorda que seja precoce iniciar o treino sistematizado aos 4-5 anos seja precoce. O debate sobre a idade de especialização na GA é antigo (BOMPA, 2000; LÉGlise, 1996, 1998; MARQUES, 1991; Nunomura, Pires \& Carrara, 2009; Watts, 2002) e estamos longe de chegar a um consenso.

Com base nas próprias experiências, há técnicos que são favoráveis à especialização das crianças entre os 4-7 anos de idade, ou seja, abaixo do que se recomenda na literatura. Estes justificam que aquelas que iniciaram cedo (quatro anos) têm postura diferente daquelas que começaram mais tarde (sete anos), e que as talentosas têm condições de começar cedo. Há aqueles contrários à ideia de que a especialização deva ser cedo, pois acreditam que a mesma leva ao esgotamento e abandono prematuros, prejudica a saúde e que a criança tão jovem necessita de muita assistência. Assim, as atividades devem estimular a formação motora geral (WEINECK, 1999). A individualidade é citada no caso de talentos, como aquelas que iniciaram mais tarde (10-11 anos de idade) e se destacaram na GA, como foi o caso da ginasta Daiane. Os técnicos também se referiram às meninas que iniciaram cedo (5-6 anos) e que aos 17 anos já encerraram a carreira. $\mathrm{O}$ relato revela a preocupação desses técnicos em prolongar o período de participação esportiva (ARaújo, 1998; GONÇALVES, 1999).

Conteúdo: como o processo de formação esportiva ocorre em longo prazo, não há motivos para apressar o ápice da ginasta, e um técnico (T9) cita: "se a menina tem sete anos hoje, ela só vai competir em 2017, então pra que exigir um duplo mortal agora?”. Mas, outro técnico (T26) argumenta: "Ninguém quer saber de investimento para médio ou longo prazo. Todo mundo quer a curto prazo", talvez referindo-se às cobranças da instituição ou do próprio sistema da GA, que permite a participação de jovens de 13 anos de idade em eventos da categoria adulta. Mas, a decisão é do técnico e, se ele não visa aos resultados imediatos, não deve queimar etapas e apressar a participação de ginastas na categoria superior.

$\mathrm{O}$ esgotamento foi muito comentado e os argumentos estão associados ao início precoce do treino especializado e às frustrações em eventos nos quais as ginastas confrontam adversários superiores. $\mathrm{O}$ risco de lesão também foi citado e está associado às demandas das categorias competitivas superiores (Pettrone \& Ricciardelli, 1987). 
Os técnicos relataram as tendências mundiais das regras da Federação Internacional de Ginástica (FIG) as quais, consequentemente, direcionam aquelas da $\mathrm{CBG}$ e das federaçôes. Um técnico (T28) comentou que, concordem ou não, eles devem seguir estas normas. Contrariamente, alguns técnicos acreditam que a FIG tem revisto a questão e há perspectivas de elevarem a idade mínima para participação das meninas nos torneios internacionais, dos atuais 16 para 18 anos de idade no próximo ciclo olímpico. O técnico (T29) cita que, atualmente, encontramos ginastas acima dos 25 anos de idade competindo e obtendo resultados expressivos no cenário internacional, o que indica que a carreira das ginastas pode avançar para a fase adulta e ser bem sucedida.

Observamos que a maioria dos técnicos tem consciência dos riscos e prejuízos da especialização precoce, mas, ao mesmo tempo, sentem-se limitados pelas regras atuais da GA. Privar as crianças de competições é eliminar um dos fatores motivacionais importantes (Hedstrom \& Gould, 2004; Lopes \& NunOmura, 2007; Relvas, 2005) e a dedicação destas aos treinos também pode perder sentido. Por outro lado, mesmo que o técnico julgue prematuro, a instituição pode exigir que as ginastas participem.

Assim, para o técnico, é um dilema que poderia ser resolvido através de esclarecimentos, aos demais envolvidos no esporte como pais e coordenadores, de que se deve priorizar e preservar a integridade das crianças. Uma sugestão é monitorar, regularmente, os parâmetros que indicam o desenvolvimento como peso corporal, medidas antropométricas, estágio maturacional, registros de lesōes, distúrbios de sono, entre outros (BRENNER \& CSMF, 2007; DAMSGAARD, 2001) e verificar se as crianças se enquadram dentro na normalidade.

\section{Setor masculino}

\section{Ideal para iniciar na GA}

Idade: as faixas etárias mencionadas são semelhantes as do setor feminino. A maioria dos técnicos acredita que seja necessário iniciar entre os 5-7 anos de idade (Arkaev \& Suchilin, 2004; Bompa, 2000) e, que aos 3-4 anos, a criança pode começar a frequentar o ambiente da GA. A formação generalizada é defendida pelos técnicos que pensam que a não-especialização nas fases iniciais garantiria a evolução posterior e não esgotaria precocemente as crianças (WEINECK, 1999). Os técnicos também citaram o papel que a Educação Física Escolar deveria prestar, ou seja, o de estimular a formação motora inicial, mas que não é cumprida em sua totalidade pela maioria das escolas.
Conteúdo: os técnicos mencionaram, também, que procuram desenvolver o gosto pela prática esportiva e afirmam que não cobram ou pressionam as crianças para que treinem.

Assim como no setor feminino, há técnicos que apontam para a realidade do país, em que a seleção rigorosa e, principalmente, o suposto limite de idade para iniciar na GA, tem impacto sobre o número de praticantes. Estes técnicos reforçam que, nas instituiçôes municipais, a filosofia é não excluir, o que é coerente, pois o número de praticantes de GA no setor masculino é ainda menor se comparado ao feminino.

Entre as instituiçõos visitadas, observamos que apenas 12 oferecem GA para os homens. Então, a exclusão daqueles que não apresentam o perfil ideal para a GA, ou que são considerados velhos para iniciar, contribuiria para diminuir o nível de participação.

Há técnicos preocupados em prolongar a participação de seus ginastas. Eles citam que as exigências do esporte competitivo, nas idades baixas, podem levar muitas crianças a desistirem cedo e antes mesmo de se destacarem na modalidade, particularmente no masculino, em que o pico de performance ocorre a partir dos 17-18 anos de idade (ARKAEV \& SUCHILIN, 2004).

\section{Ideal para especializar na GA}

Idade: contrário ao setor feminino, a literatura tem revelado o início mais tardio da especialização entre os meninos (Sobral, 1994). Mas, assim como no setor feminino, os técnicos se vêem presos aos regulamentos das competições, e muitos pensam que estas aconteçam muito cedo. $\mathrm{O}$ menino pode começar a competir com nove anos de idade. E, segundo um técnico (T2) são necessários, no mínimo, dois anos para que esteja preparado para competir. Assim, a maioria dos técnicos cita que os ginastas deveriam iniciar a especialização por volta dos sete anos de idade para terem mais chances de resultados na sua categoria. O quadro é ainda mais delicado, pois as crianças podem competir em categorias superiores no último ano de sua categoria, o que eleva o grau de dificuldade das regras. O fato pode aumentar a pressão para que a especialização ocorra, pois, devido à escassez de ginastas, estes muitas vezes são obrigados a participar em outras categorias para completar as equipes (Nunomura, Pires \& Carrara, 2009). O treino da GA competitiva é orientado pelas regras das competiçõos. Nas categorias inferiores, as federações e a CBG criam regras adaptadas da FIG e festivais com exigências menores, a fim de permitir uma participação mais segura das faixas etárias mais baixas. Porém, essa é 
uma entre as diversas adaptaçóes necessárias no esporte para que beneficie e se adeque às crianças e aos jovens.

Os técnicos mencionam o processo de crescimento e de maturação que, no masculino, é favorável, pois, com a entrada na puberdade, eles melhoram a performance, devido ao ganho de massa muscular e de força (BALE \& GOODWAY, 1990). Ao contrário do feminino, em que as ginastas têm dificuldades para progredir devido ao aumento da massa adiposa e das proporçóes corporais. Por outro lado, os técnicos consideram que seja uma fase delicada, pois coincide com o período em que muitos jovens necessitam ingressar no mercado de trabalho para ajudar nas despesas familiares. Outro fator de impacto nesta fase é a prioridade atribuída à formação profissional, mas que não é contestada pelos técnicos. A GA não é um esporte profissional e a ansiedade para ingressar no mercado de trabalho é normal entre os jovens brasileiros e, muitas vezes, uma necessidade.

Conteúdo: os técnicos mencionaram a formação da base motora e observamos que as crianças são encaminhadas ao treinamento diário entre os 7-9 anos de idade e, conforme a literatura, este fato caracteriza o treinamento especializado, conforme a literatura (Claessens et al., 1992; Silva, Fernandes \& Celani, 2001).

É interessante o depoimento de (T4), que relata que antes pregava o início e a especialização precoce das crianças, mas, atualmente, percebe que se elas iniciam muito cedo, perdem rapidamente o interesse pela GA. Alguns técnicos citaram o esgotamento das crianças e argumentaram que a prática da GA é monótona e repetitiva e que cansa facilmente. $\mathrm{O}$ aspecto lúdico também foi mencionado, ainda que em menor expressão, mas revela a preocupação do técnico em atender às necessidades da idade, que é de brincar e de se divertir (Bee, 2003; Gallahue \& Ozmun, 2005).

Outro relato interessante foi o do técnico (T8): "No nosso meio é utopia né, mas o ideal é que o ginasta tenha um bom trabalho psicomotor no início, e que passe por um bom treinamento de preparação técnica básica, que depois vai desenvolvendo para diferentes fases e passando pelos treinadores que tenham conhecimento técnico adequado para poder evoluir o trabalho". O depoimento revela que o técnico tem consciência do ideal e da necessidade da formação de base, mas, que poucos profissionais e ele próprio, não têm oportunidade ou condiçôes de realizar. As exigências das instituições para que os ginastas participem de competições pode ser uma das justificativas (Silva, Fernandes \& Celani, 2001).

\section{Ponto de vista sobre a "especialização precoce"}

Idade: sobre a especialização precoce na GA masculina, os técnicos citaram que a ideia de que se deve iniciar e especializar cedo no treinamento não existe mais no país.

Conteúdo: os técnicos condenam o esgotamento, seja físico ou psicológico, e sugerem que se desenvolva a coordenação e os movimentos básicos nas crianças menores (4-5 anos), com baixo volume de atividades (ARKAEv \& Suchilin, 2004) e sem exigências ou pressões (WEINECK, 1999). Eles acreditam que, se as crianças estiverem envolvidas no treinamento sistematizado e especializado, elas também serão inseridas em situações competitivas. E, assim, seriam duas condições demandadoras para as quais as crianças poderiam não apresentar condições de responder com sucesso.

\section{Considerações finais}

A partir do exposto, foi possível observar alguns ângulos do processo de formação esportiva na GA do Brasil. O sistema competitivo em si merece considerações, pois, muitos técnicos citaram inadequações. O quadro não é muito diferente nas demais modalidades, mas, em especial na GA, é ainda mais crítico, pois envolve crianças muito jovens. Por que iniciar as crianças tão jovens no sistema competitivo? Sobre estas críticas, a própria FIG tem respondido com a elevação da idade mínima de participação em torneios internacionais, conforme citado anteriormente. Mesmo que haja regras para a idade de participação nas competições, não há necessidade de que as crianças experimentem todas essas fases. A frustração acumulada de uma série de participações sem sucesso, por não estar devidamente preparado, pode ser mais prejudicial do que participar menos e ter oportunidade de experimentar o sucesso. As regras adaptadas às categorias se aproximam mais à realidade dos ginastas e, potencialmente, levam a uma maior ocorrência de sucesso, o que pode estimular a participação prolongada no esporte.

Em geral, os técnicos estão conscientes de que, na fase inicial, é necessário desenvolver uma base motora geral através de atividades lúdicas e, também, moderar as cargas de treinamento nas fases iniciais. 
Há aqueles que dizem seguir modelos e padrões sem discutir as suas adequações. Apesar de haver programas-modelo de GA para se orientarem, os técnicos não devem se apoiar somente nestes, pois há particularidades do nosso contexto que devem ser atendidas. Assim, eles deveriam fazer esse julgamento e adaptações com muito critério. Foi citada a falta da Educação Física escolar para promover as experiências motoras básicas e o gosto pelo exercício físico e pela prática esportiva. Então, não é possível seguir, integralmente, os modelos internacionais, pois os níveis de formação esportiva na GA foram estabelecidos a partir do pressuposto de que as crianças têm uma base motora geral homogênea.

A contradição na prática de alguns técnicos ficou evidente, pois, ainda que mencionem a importância de formar uma base motora, do amadurecimento emocional e cognitivo, ao mesmo tempo iniciam seus ginastas em treino especializado muito antes de terem atingido um grau de maturação nestas dimensões. Um dos argumentos defendidos pelos técnicos é que esses ginastas são talentos e, portanto, são capazes de responder às demandas do esporte de alto nível, o que confirma o pressuposto de Sobral (1994). A disseminação dos programas de identificação e de desenvolvimento de talentos levou muitos técnicos a acreditarem que todos os atletas podem ser enquadrados em dois grupos: "talentosos" ou "nãotalentosos". Assim, pressupõe-se que os talentosos são aqueles com maiores chances de vencer no esporte. Os diagnósticos não preconizam os eventos imprevisíveis como lesões, condições psicológicas, mudança de residência, troca de técnicos, etc. Tudo tem uma parcela de influência e, por vezes, aquele classificado como não-talentoso pode apresentar, ao longo da carreira esportiva, condiçōes muito mais favoráveis do que o talentoso. Ainda que sejam talentosos, os atletas têm limites e estes devem ser respeitados. $\mathrm{O}$ fato de ser talentoso não significa que esteja motivado a ser submetido às mesmas demandas de atletas adultos.

Observamos, principalmente, no setor feminino, que os técnicos acreditam que as ginastas deveriam começar bem cedo, antes da puberdade, pois, após esta fase, haveria poucas chances de sucesso. Certamente, as vantagens biomecânicas são incontestáveis. Mas, por outro lado, com o avanço da idade, qualidades desejáveis também podem surgir como, por exemplo, a maturidade psicológica. Isto pode compensar os aspectos negativos como o ganho de massa e altura.

É importante ressaltar que o início na GA, com a finalidade de familiarizar os praticantes com o ambiente da prática e receber estímulos físicos e motores gerais, não incorre em danos às crianças mais jovens. E, potencialmente, estas poderão se destacar na modalidade, assim como aquelas que não tiveram oportunidade de iniciar cedo, desde que sejam adequadamente orientadas. A maturação e o crescimento são processos previsíveis para todos, porém, ocorrerão em momentos e intensidades distintos. Um técnico consciente e esclarecido será capaz de atuar positivamente para que essas mudanças sejam incorporadas na rotina esportiva sem comprometer a participação e o interesse pelo esporte. Esclarecer os atletas dessas mudanças e do impacto sobre a sua performance e resultados ameniza e facilita a adaptação e diminui a possibilidade de abandono do esporte.

Em geral, no período de ingresso no ensino superior, muitos atletas brasileiros estão encerrando sua carreira esportiva, pois são raros aqueles que recebem apoio financeiro para arcar com os custos ou bolsas de estudo das próprias Universidades. No nosso país, muitos atletas também são obrigados a ingressar no mercado de trabalho, pois a dedicação ao esporte não lhes garante as condiçōes de sustento para as necessidades básicas. Assim, não é realista esperar que o atleta atinja a maioridade para começar a se destacar no esporte, pois, no nosso caso, é justamente o período em que ocorre o término da sua carreira. Uma sugestão seria adotar um sistema integrado entre as instituiçõos esportivas e de ensino para apoiar os atletas. Pode-se utilizar o parâmetro de rendimento esportivo combinado ao de necessidade social, assim como aquele aplicado pelo Ministério do Esporte. As instituições, Federações e a Confederação deveriam atrair e incentivar o empresariado a apoiar os atletas, os quais poderiam se beneficiar com a dedução fiscal e como meio de divulgação de sua marca.

A formação esportiva é um processo longo e, assim, o imediatismo ou a supressão de qualquer uma de suas fases terá consequências, seja em médio ou longo prazo. Certamente, as crianças e os jovens serão aqueles que mais sofrerão as consequências negativas da especialização precoce, caso esta seja a opção dos técnicos, pois geralmente serão acompanhadas por altas demandas, pressões por rendimento e resultados imediatos. E mais, provavelmente, estas crianças e jovens encerrarão a carreira esportiva e levarão para o futuro experiências pouco encorajadoras para se manterem fisicamente ativos. E, provavelmente, estes estarão pouco motivados a incentivar as gerações futuras à participação esportiva. $\mathrm{Ou}$, poderão se tornar técnicos e acreditar que a especialização precoce seja inevitável $\mathrm{e}$, consequentemente, procederão da mesma forma.

É possível aproximarmos do ideal de formação esportiva, mas, as mudanças devem ser graduais para 
que o sistema atual não entre em colapso. É fato que os técnicos precisam manter suas posiçōes e, para justificálas, devem competir e obter resultados que satisfaçam as instituiçōes, os pais e, se for o caso, os patrocinadores. A alternativa seria esclarecê-los sobre as particularidades do Esporte e da GA. Reportar progressos individuais dos atletas, seu grau de satisfação no esporte, suas conquistas e superações individuais pode amenizar a ênfase sobre a competição e os resultados.
Os técnicos e demais envolvidos no esporte não devem poupar esforços para proteger os atletas, para prolongar sua participação e, principalmente, para proporcionar-lhes experiências positivas no esporte. Mesmo que o atleta não seja um destaque, se bem orientado, ele poderá incentivar gerações futuras. E, eventualmente, poderá surgir um campeão, ainda que não seja este o principal objetivo da participação esportiva.

\section{Abstract}

Artistic gymnastics and early specialization: too young to specialize, too old to be a champion!

In Artistic Gymnastics we usually observe very young gymnasts committed to training and competition, and getting outstanding results in the international context. Therefore, this discipline has been frequently targeted for the doubtfulness of its practices and the actual need to start systematic training at earlier ages. However, in Brazil, we could not find any data regarding initiation and specialization in Artistic Gymnastics so far. The purpose of this study was to investigate and to analyse the point of view of coaches regarding the ideal age to initiate and specialize in Artistic Gymnastics and their concerns. We interviewed 46 Brazilian coaches, who are coaching developing young competitive gymnasts at all levels of skills. The content analysis technique proposed by BARDIN (2001) was used for data treatment. The results showed that both boys and girls start to practice at early age. The women and men gymnasts' coaches revealed that the early specialization occurs due to the inherent nature of the Artistic Gymnastics, the age of participation in the official competition, and the required time to develop a gymnast until his/her readiness to compete. Particularly, regarding the male gymnasts, some of them need to start working, and coaches feel pressured to pursuit results before the period when dropout begins.

UNITERMS: Artistic gymnastics; Training; Specialization; Early specialization.

\section{Referências}

ARAÚJO, C.M. O treino dos jovens ginastas. Horizonte, Lisboa, v.15, n.85, p.1-12, 1998. Caderno Especial.

ARKAEV, L.; SUCHILIN, N. How to create champions. Oxford: Meyer \& Meyer Sport, 2004.

BALE, P.; GOODWAY, J. Performance variables associated with the competitive gymnast. Sports Medicine, Auckland, v.10, n.3, p.139-45, 1990.

BALYI, I. O desenvolvimento do praticante a longo prazo: sistema e soluções. Treino Desportivo, Lisboa, n.23, p.22-27, 2003. BARDIN, L. Análise de conteúdo. Lisboa: Ediçôes 70, 2001.

BEE, H. A criança em desenvolvimento. Tradução de Maria Veronese. Porto Alegre: Artmed, 2003.

BOMPA, T. O. Total training for young champions. Champaign: Human Kinetics, 2000. p.1-29.

BRENNER, J.; COUNCIL ON SPORTS MEDICINE AND FITNESS (CSMF). Overuse injuries, overtraining, and burnout in child and adolescent athletes. Pediatrics, Elk Grove Village, v.119, n.6, p.1242-45, 2007.

CARAZZATO, J.G. A criança e o esporte: idade ideal para o início da prática esportiva competitiva. Revista Brasileira de Medicina do Esporte, São Paulo, v.1, n.4, p.97-101, 1995.

CHAURRA, J.T.; ZULUAGA, L.F.A.; PEÑA, N.M. Escuelas de formación deportiva com enfoque integral y entrenamiento deportivo infantil: uma experiencia investigativa. Armênia: Kinesis, 1998.

CLAESSENS, A.L.; MALINA, R.M.; LEFEVRE, J.; BEUNEN, G.; STIJNEN, V.; MAES, H.; VEER, F.M. Growth and menarcheal status of elite female gymnasts. Medicine \& Science in Sports \& Exercise, Madison, v. 24, n.7, p.755-63, 1992. 
COELHO, O. Pedagogia do desporto: contributos para uma compreensão do desporto juvenil. Lisboa: Livros Horizonte, 1988. DAMSGAARD, R. Children in competitive sports: clinical implications. FIS Medical Committee Educational Series, 2001. Disponível em: <http://www.fis-ski.com/data/document/children-competiton-damsgaard.pdf>. Acesso em: 20 ago. 2008. GALDINO, M.L.; MACHADO, A.A. Pontos e contrapontos acerca da especialização precoce nos esportes. In.: MACHADO, A.A. (Org.) Especialização esportiva precoce: perspectivas atuais da psicologia do esporte. Jundiaí: Fontoura, 2008, p.129-47. GALlaHUE, D.; OZMUN, J. Compreendendo o desenvolvimento motor: bebês, crianças, adolescentes e adultos. Tradução de Maria Araújo. São Paulo: Phorte, 2005.

GONÇALVES, C. Um olhar sobre o processo de formação do jovem praticante. Treino Desportivo, Lisboa, n.2, p.42-8, 1999. Edição Especial.

HEDSTROM, R.; GOULD, D. Research in youth sports: critical issues status. Michigan: Institute for the Study of Youth Sports, 2004. Disponível em: <http://ed-web3.educ.msu.edu/ysi/project/CriticalIssuesYouthSports.pdf>. Acesso em: 20 ago. 2008. LÉGLISE, M. Children and high-level sport. Olympic Review, Lausanne, v.7. n.25, p.52-5, 1996.

. Limits on young gymnasts' involvement in high-level sport. Technique, Indianapolis, v.18, n.4, p.8-14, 1998.

LOPES, P.; NUNOMURA, M. Motivação para a prática e permanência na ginástica artística de alto nível. Revista Brasileira de Educação Física e Esporte, São Paulo, v.21, n.3, p.177-87, 2007.

MARQUES, A.T. A especialização precoce na preparação desportiva. Treino Desportivo, Lisboa, n.19, p.9-15, 1991.

McCULLICK, B.; BELCHER, D.; SCHEMPP, P. What works in coaching and sport instructor certification programs? The participants' view. Physical Education and Sport Pedagogy, Florence, v.10, n.2, p.121-37, 2005.

NUNOMURA, M.; PIRES, F; CARRARA, P. Análise do treinamento na ginástica artística brasileira. Revista Brasileira de Ciências do Esporte, Campinas, v.31, n.1, p.25-40, 2009.

PETTRONE, F.; RICCIARDELLI, E. Gymnastic injuries: the Virginia experience 1982-83. American Journal of Sports Medicine, Chicago, v.15, n.1, p.59-62, 1987.

RELVAS, H. Adjustments within coaches and young athletes regarding sport participation. Treino Desportivo, Lisboa, n.4, p.4-7, 2005. RICHARDS, E.J.; ACKLAND, R.T.; ELLIOTT, B.C. The effect of training volume and growth on gymnastic performance in young women. Pediatric Exercise Science, Nedlands, v.11, n.4, p.349-63, 1999.

SEABRA, A.; CATELA, D. Maturação, crescimento físico e prática desportiva em crianças. Horizonte, Lisboa, v.14, n.83, p.15-7, 1998. SILVA, F.S.; FERNANDES, L.; CELANI, F.O. Desporto de crianças e jovens: um estudo sobre as idades de iniciação. Revista Portuguesa de Ciências do Desporto, Porto, v.1, n.2, p.45-55, 2001.

SOBRAL, F. Desporto infantil: prontidão e talento. Braga: Horizonte, 1994.

TSUKAMOTO, M.H.C.; NUNOMURA, M. Aspectos maturacionais de atletas de ginástica olímpica do sexo feminino. Motriz, Rio Claro, v.9, n.2, p.119-26, 2003.

WATTS, J. Perspectives on sport specialization. Journal of Physical Education, Recreation and Dance, Reston, v.73, n.8, p.32-7, 2002. WEINECK, J. Treinamento ideal. Tradução de Beatriz Maria Romano Carvalho. São Paulo: Manole, 1999.

ZAKHAROV, A. Ciência do treinamento desportivo. Rio de Janeiro: Grupo Palestra Sport, 1992.

\section{Nota}

Apoio: FAPESP.

\begin{tabular}{|c|c|}
\hline $\begin{array}{r}\text { ENDEREÇo } \\
\text { Myrian Nunomura } \\
\text { Escola de Educação Física e Esporte de Ribeirão Preto - USP } \\
\text { Av. dos Bandeirantes, 3900 } \\
14040-907 \text { - Ribeirão Preto - SP - BRASIL } \\
\text { e-mail: mnunomur@usp.br }\end{array}$ & $\begin{array}{l}\text { Recebido para publicação: 14/04/2009 } \\
\text { Revisado em: 04/01/2010 } \\
\text { Aceito: 07/01/2010 }\end{array}$ \\
\hline
\end{tabular}

